\title{
Childbirth Pain and Post-Partum Depression: Does Labor Epidural Analgesia Decrease This Risk?
}

\author{
Daniele C Parise' \\ Caitlin Gilman² \\ Matthew A Petrilli $\mathbb{D}^{3}$ \\ Dolores Malaspina ${ }^{4}$
}

'Scope Anesthesia of North Carolina, Charlotte, NC, USA; ${ }^{2}$ Department of Pediatrics, Montefiore Children's Hospital, Einstein Medical School, New York, NY, USA; ${ }^{3}$ Sentara Behavioral Health Specialists, South Boston, VA, USA; ${ }^{4}$ Department of Psychiatry, Icahn School of Medicine at Mt. Sinai, New York, NY, USA
Correspondence: Dolores Malaspina Department of Psychiatry, Icahn School of Medicine at Mt. Sinai, One Gustave L Levy Place, Box 1230, New York, NY, 10039 , USA

Tel +I (7I8) 877-5708

Email Dolores.malaspina@mssm.edu

\begin{abstract}
Post-partum depression (PPD) is a common complication of pregnancy worldwide with a prevalence as high as $15 \%$ in some countries. Pain has been identified as a risk factor for major depression; however, the relationship between labor-related pain and PPD is less understood. This article sought out to examine the relationship between pain and PPD, examining whether there is a correlation that reducing pain through epidural analgesia can lower the risk for PPD. A PubMed database search was performed using the keywords "postpartum depression" and "labor epidural". Multiple articles including 2 meta-analyses were evaluated for the association between post-partum depression and epidural analgesia for labor. Although there is evidence supporting labor epidural analgesia reducing PPD, many studies including the meta-analyses did not uphold the hypothesis. More well-designed studies on this topic need to be investigated in order to substantiate the current evidence in the literature.
\end{abstract}

Keywords: labor pain, labor epidural, post-partum depression, consult liason psychiatry, pain management, reproductive psychiatry

\section{Introduction}

Post-partum depression (PPD) is one of the most common complications of pregnancy worldwide. Estimates vary, but prevalence is believed to be as high as $15 \%$ with some of the highest estimates in lower income countries. ${ }^{1,2}$ PPD is distinct from the "baby blues" which describes mild feelings of anxiety, fatigue and unhappiness that afflict up to $80 \%$ of new mothers for several weeks and then spontaneously remit. By contrast, untreated depressive symptoms in the peripartum period are associated with inabilities of mothers to care for their families or themselves and impaired newborn attachment, which can have serious consequences for the offspring. ${ }^{1}$ Without treatment, PPD can last for months or years: approximately $20 \%$ of mothers with PPD remain depressed after 1 year postdelivery and $13 \%$ are still depressed after 2 years. ${ }^{3}$ In addition, $40 \%$ of women who suffered from PPD will relapse in subsequent pregnancies. ${ }^{3}$ As such, PPD poses a significant burden on both the mother and family, and identifying risk factors that can be mitigated can be beneficial in reducing this disease burden.

Women with a personal or family history of major depression or bipolar disorder, a prior postpartum depression and stressful life events, including medical issues in their newborn have a heightened risk of PPD, which can occur regardless 
of ethnicity, education or age. ${ }^{1-4}$ Another important risk factor is labor and delivery complications, particularly pain. Although the bidirectional relationship between pain and depression is well established, ${ }^{5}$ research on the relationship between labor pain (intrapartum) and the subsequent emergence of PPD is minimal. Nonetheless, as medical advancements can improve labor and delivery experiences and appropriate analgesia can greatly minimize pain, this remains an important clinical question. Medical management to minimize intrapartum pain may present a significant opportunity for the primary prevention of PPD. Parents who are discussing which labor and delivery options to choose with their clinician might opt to avoid interventions associated with the risk for PPD. This review provides information based on the published literature between the association of intrapartum pain and PPD. It builds two recent meta-analyses of such studies, critically analyzing research thus far to discuss the hypothesis that reducing labor pain through epidural analgesia may be associated with a lower risk of PPD.

\section{Materials and Methods}

On 11/1/2020, a PubMed search was performed using the terms "labor epidural" and "post-partum depression" in conjunction in order to identify relevant articles pertaining to the topic of interest. No specific search dates were used in identifying pertinent studies. Studies were selected for inclusion based on their ability to accurately show a relationship between labor epidural analgesia and post-partum depression. Both studies with positive and negative relationships between these two variables were reviewed and those with the most strength were the articles selected for review. Strength of a journal article was based on whether the paper was peer-reviewed, effectively answered both the primary researchers and our questions, and had a well-designed study with limited biases or confounders. Equal emphasis was placed on finding strong studies showing an association between labor epidural and PPD as well as those showing no association between these two variables. After thorough evaluation, 10 studies were selected for the literature review, including two meta-analyses (Table 1). Five publications supported a role for epidural anesthesia in decreasing the risk for PPD, whereas five others, including the two metaanalyses refuted the association. Three papers discussed the increasing incidence of PPD associated with severe postpartum pain, supporting the contention that painful births are plausibly related to the risk for PPD; however, this type of pain may significantly differ from acute intrapartum pain.

\section{Post-Partum Depression Overview}

Post-partum depression is included in the Diagnostic and Statistical Manual for Psychiatric Diagnosis (DSM-5) as a specifier for major depressive disorder. It requires a "peripartum onset", defined as commencing within four weeks of the delivery. ${ }^{2}$ However, clinical research studies of PPD often include depressive episodes that emerged up to one year post-delivery. ${ }^{1}$ In addition to the more classic depressive symptoms of low mood, anhedonia, and poor sleep, altered appetite and hopelessness, PPD can further include feelings of being overwhelmed, thoughts of being a bad mother, and obsessional preoccupations with the newborn's wellbeing. ${ }^{1}$

Diagnosing PPD is solely based on clinical information. Many institutions have implemented the Edinburgh Postnatal Depression Scale (EPDS) as an effective screening method. This screening tool is endorsed by both the American College of Obstetricians and Gynecologists and the American Academy of Pediatrics. ${ }^{1}$ This 10 -Item questionnaire has a sensitivity of $80 \%$ for detecting PPD. ${ }^{6}$ A score greater than 10 is indicative of a positive screen indicating the need for a further evaluation. Treatment depends on the severity and other variables, and includes specific psychotherapies, enhanced supports and psychotropic medication. ${ }^{1}$

As mentioned, the strongest risk factor for PPD is a prior history of a mood disorder; however, PPD's exact etiology remains unclear. Research suggests that the rapid decline in reproductive hormones post-delivery may play some role. ${ }^{1,7}$ In deliveries with severe labor pain and anxiety, endogenous catecholamines are released. These can interfere with the progress of labor by inhibiting uterine activity, resulting in dystocia and other associated complications. ${ }^{8}$ By contrast, oxytocin release decreases levels of anxiety and aggression and, may thereby decrease the risk for depression. ${ }^{9}$

Appropriate usage of epidural analgesia can allow for effective pain management and assist in the women's participation in the birthing process if pain had limited her engagement. ${ }^{10}$ In addition to its use for pain management and reducing catecholamine release, epidural analgesia can be administered with exogenous oxytocin to facilitate uterine contractions. ${ }^{9}$ Effective methods of analgesia can increase the likelihood of positive psychological outcomes. In order to better understand epidural analgesia's relationship to PPD, its mechanism and efficacy profile will be discussed. 
Table I Studies Selected for Review

\begin{tabular}{|c|c|c|c|}
\hline Title, Author(s), Year & $\begin{array}{l}\text { Sample } \\
\text { Size }\end{array}$ & $\begin{array}{l}\text { Study } \\
\text { Design }\end{array}$ & Main Findings \\
\hline $\begin{array}{l}\text { Kounanis et al } 2019 \\
\text { "Labor epidural analgesia and the risk of postpartum } \\
\text { depression: Ameta-analysis of observational studies." }\end{array}$ & 85,928 & $\begin{array}{l}\text { Meta-analysis } \\
\text { II articles } \\
\text { included }\end{array}$ & $\begin{array}{l}\text {-No association between epidural analgesia and PPD (pooled } \\
\text { adjusted OR } 1.03,95 \% \mathrm{Cl} 0.77-1.37 \text { ) }\end{array}$ \\
\hline $\begin{array}{l}\text { Almeida et al } 2020 \\
\text { "The Association between Labor Epidural Analgesia and } \\
\text { Depression: A Systematic Review and Meta-Analysis." }\end{array}$ & 4,442 & $\begin{array}{l}\text { Meta-analysis } \\
9 \text { articles } \\
\text { included }\end{array}$ & $\begin{array}{l}\text {-No association between epidural analgesia and PPD (OR } \\
\text { I.02, } 95 \% \mathrm{Cl}, 0.62-1.66)\end{array}$ \\
\hline $\begin{array}{l}\text { Hiltunen et al } 2004 \\
\text { "Does pain relief during delivery decrease the risk of } \\
\text { postnatal depression?" }\end{array}$ & 185 & $\begin{array}{l}\text { Prospective } \\
\text { follow-up } \\
\text { study }\end{array}$ & $\begin{array}{l}\text {-The adjusted risk of depressive scores during the Ist } \\
\text { postnatal week was decreased in the epidural/paracervical } \\
\text { group compared to deliveries without analgesia (OR } 0.25 \text {, } \\
95 \% \mathrm{Cl}, 0.09-0.72) \\
\text {-No difference at } 4 \text { months postpartum }\end{array}$ \\
\hline $\begin{array}{l}\text { Ding et al } 2014 \\
\text { "Epidural Labor Anesthesia is Associated with Decreased } \\
\text { Risk of Postpartum Depression: A Prospective cohort study". }\end{array}$ & 214 & $\begin{array}{l}\text { Prospective } \\
\text { cohort study }\end{array}$ & $\begin{array}{l}\text { PPD was seen in } 14 \% \text { of women who received epidural labor } \\
\text { analgesia and } 34.6 \% \text { of those without epidural }(\mathrm{p}<0.000 \mathrm{I}) \\
\text {-Statistically significant correlation that epidural was } \\
\text { associated with a decreased risk of postpartum depression }\end{array}$ \\
\hline $\begin{array}{l}\text { Suhutharan et al } 2016 \\
\text { "Investigating analgesic and psychological factors associated } \\
\text { with risk of postpartum depression development: a case- } \\
\text { control study". }\end{array}$ & 479 & $\begin{array}{l}\text { Case control } \\
\text { study }\end{array}$ & $\begin{array}{l}-68.7 \% \text { of women who received epidural analgesia, the risk } \\
\text { for PPD was significantly lower than those without an } \\
\text { epidural: } 10.0 \% \text { vs } 19.3 \% \text { (OR } 0.47, \mathrm{Cl} 0.27-0.8, P=0.0078 \text { ). } \\
\text {-Absence of epidural analgesia was associated with almost } \\
\text { double the risk of PPD (adjusted OR I.95, CI I.04-3.66, } \\
P=0.0367 \text { ). }\end{array}$ \\
\hline $\begin{array}{l}\text { Lim et al } 2018 \\
\text { "Labor Analgesia as a Predictor for Reduced Postpartum } \\
\text { Depression Scores: A Retrospective Observational Study". }\end{array}$ & 201 & $\begin{array}{l}\text { Retrospective } \\
\text { observational } \\
\text { study }\end{array}$ & $\begin{array}{l}\text {-Linear regression demonstrated an association between } \\
\text { higher improvements in pain and lower EPDS score }(r=0.025 \text {; } \\
P=0.002) \text {. }\end{array}$ \\
\hline $\begin{array}{l}\text { Nahirney et al } 2017 \\
\text { "Investigating analgesic and psychological factors associated } \\
\text { with risk of postpartum depression development: a case- } \\
\text { control study". }\end{array}$ & 479 & $\begin{array}{l}\text { Case control } \\
\text { study }\end{array}$ & $\begin{array}{l}\text {-Epidural use was not significantly associated with PPD. - } \\
\text { There was a wide confidence interval }(0.39-2.77) \text { and may be } \\
\text { masking a statistically relevant association }\end{array}$ \\
\hline $\begin{array}{l}\text { Wu et al } 2018 \\
\text { "Association between Intrapartum Epidural Use and } \\
\text { Maternal Postpartum Depression Presenting for Medical } \\
\text { Care: a Population-based, Matched Cohort Study" }\end{array}$ & 40,303 & $\begin{array}{l}\text { Population- } \\
\text { based, } \\
\text { matched } \\
\text { cohort study }\end{array}$ & $\begin{array}{l}\text {-Intrapartum epidural use was not associated with maternal } \\
\text { postpartum physician or hospital visits or self-harm. }\end{array}$ \\
\hline $\begin{array}{l}\text { Sun et al } 2020 \\
\text { "Epidural Labor Analgesia Is Associated with a Decreased } \\
\text { Risk of the Edinburgh Postnatal Depression Scale in Trial of } \\
\text { Labor after Cesarean: A Multicenter, Prospective Cohort } \\
\text { Study." }\end{array}$ & 423 & $\begin{array}{l}\text { Multicenter, } \\
\text { prospective } \\
\text { cohort study }\end{array}$ & $\begin{array}{l}\text {-Epidural analgesia during labor was significantly associated } \\
\text { with a decreased risk of depression at both } 48 \text { hours and } 42 \\
\text { days after delivery for TOLAC (OR, } 0.209 ; 95 \% \mathrm{Cl}, 0.096- \\
0.429 ; P<0.001) \text { and }(\mathrm{OR}, 0.235 ; 95 \% \mathrm{Cl}, 0.113-0.469 ; P< \\
0.00 \mathrm{I})\end{array}$ \\
\hline $\begin{array}{l}\text { Orbach-Zinger et al } 2018 \\
\text { "The Relationship Between Women's Intention to Request } \\
\text { a Labor Epidural Analgesia, Actually Delivering With Labor } \\
\text { Epidural Analgesia, and Postpartum Depression at } 6 \text { Weeks: } \\
\text { A Prospective Observational Study." }\end{array}$ & 1326 & $\begin{array}{l}\text { Observational } \\
\text { study }\end{array}$ & $\begin{array}{l}\text { - No statistical difference from individuals that were } \\
\text { diagnosed with PPD }(6.6 \%) \text { at } 6 \text { weeks that wanted an } \\
\text { epidural but did not receive one versus the rest of the } \\
\text { cohort (RD }=1.8 \%, 95 \% \mathrm{Cl},-0.03-0.07, \mathrm{P}=0.37 \mathrm{l}) \text {. }\end{array}$ \\
\hline
\end{tabular}

Note: This table provides an overview for the 10 various studies included in this review highlighting the heterogeneity and various findings.

\section{Epidural Analgesia Uses, Delivery and Mechanism of Action}

The use of epidural analgesia in the US tripled between 1981 and 2001 , with $60 \%$ of women using this technique in large hospitals in 2001. ${ }^{11}$ Other methods of pain relief in labor include transcutaneous electrical nerve stimulation
(TENS), parenteral narcotics and inhalation agents (Nitrous Oxide). Many studies show limited effectiveness and patient satisfaction with these analgesic regimens. ${ }^{10}$ By contrast, central neuraxial analgesia is a versatile method of labor analgesia and the current gold standard technique for pain control in obstetrics. ${ }^{12}$ Both patient 
satisfaction with birth experience and pain control are greater with neuraxial techniques. ${ }^{11}$ Local anesthetic injected into the epidural space bind and inhibit the sodium $(\mathrm{Na}+)$ channels of small postganglionic sympathetic fibers as well as inhibiting sensory and motor fibers. Blocking sensory fibers of the spinothalamic tract and sympathetic nerve fibers diminishes the painful stimulus of labor contractions and cervical dilation that ideally occurs at the first (T10-L1 level) and second stages of labor (S2-S4). Opioids work synergistically with local anesthetics, crossing the dura and binding to opioid receptors in the substantia gelatinosa of the spinal cord.

The techniques for labor epidural analgesia include direct epidural, combined spinal-epidural (CSE), and dural punctureepidural (DPE) procedures. For the epidural alone approach (most common), an epidural needle is inserted into the epidural space after identified by landmarks and the loss of resistance technique. A catheter is inserted via the needle into the epidural space to ensure that analgesia is available throughout labor. The epidural catheter allows a bolus administration or continuous epidural infusion of a local anesthetic and opioid mixture. The CSE and DPE approaches create a dural hole with a spinal needle through the epidural needle with injection of medication into the intrathecal space for the CSE, whereas no medication injected intrathecally for the DPE. Both of these techniques speed the onset of sensory block and increase the likelihood of bilateral spread while still having an epidural catheter in place. The option of patient controlled epidural analgesia (PCEA) allows the patient to administer a bolus dose of medication for breakthrough pain. On the negative side, rare side effects of epidural analgesia include slightly longer labor (although recently debunked by a study from Shen et al), greater need for instrumental delivery, higher risk of labor complications, acute hypotension, headaches, dural puncture complications and, very rarely, paralysis, infection or epidural hematoma. ${ }^{13,14}$ Despite these rare risks, it's considered to be most highly effective pain management strategy during labor with the ability of being able to use it for cesarean delivery, cervical laceration repair, or even inadequate pain relief post-cesarean section especially in chronic pain patients. ${ }^{11}$

\section{Results/Data Analysis}

Childbirth can be associated with severe pain and intensive stress. ${ }^{15}$ The relationship between labor pain and development of PPD has been proposed but the association has not been well studied. In one study, pain severity was associated with an increased incidence of depressive symptoms three days post- delivery. ${ }^{15}$ Much of the established literature shows an increased risk of PPD in women who experience significant postpartum pain but lacking for intrapartum pain. More recently, Lim et al revealed perinatal pain during multiple time points including prenatal, intrapartum, and postpartum independently predicts six-week EPDS scores. ${ }^{16}$ Eisenach et al demonstrated that acute postpartum pain severity predicted a 3-fold increased risk for PPD at 8 weeks. ${ }^{5}$ A large Canadian cohort of 5,614 women assessed for PPD using a cutoff score of 13 on the EPDS (Edinburgh Postnatal Depression Scale) found an increased risk of PPD at 3 months in women reporting prolonged perinatal pain. ${ }^{17}$ Furthermore, the odds of screening positive for PPD showed a dose-response association between the number of types of perinatal pain and PPD symptoms: with the odds of 1.7 (95\% CI 1.3-2.2) for one type of pain and increasing to 4.2 (95\% CI $0.07-0.25)$ for women with 3 or greater types of perinatal pain.

It is feasible to suggest that mitigation of labor pain through usage of epidural analgesia may decrease the incidence of PPD similar to mitigation of severe postpartum pain as evidenced in the above studies. A 2019 meta-analysis by Kounanis et al sought to find a statistically significant benefit to usage of epidural analgesia by evaluating the limited amount of studies that have been published. ${ }^{18}$ Using the Preferred Reporting Items for Systematic Reviews and Meta-Analysis (PRISMA), 11 articles met inclusion criteria with a total sample size of 85,928 . In all of these studies except one, PPD was assessed through the administration of the EPDS scale, although with varying criteria for cutoff scores, and several utilized DSM-IV criteria. The majority of studies were prospective observational studies with one analysis based on findings from a population-based cohort ${ }^{8}$ and another using a retrospective case control design. ${ }^{10}$

Analysis from the study did not confirm an association between epidural analgesia and PPD (pooled adjusted OR $1.03,95 \%$ CI $0.77-1.37$ ). The significant strengths of the metaanalysis include its accepting and merging all studies that employed valid outcomes and exposures, including use of screening tools to detect PPD, and information on whether or not epidural analgesia was used. ${ }^{18}$ However, there are significant limitations to this evaluation. In particular, the studies that were included were highly heterogeneous, and did not perhaps adequately consider confounding factors. To appreciate this heterogeneity, this review will elaborate further upon the studies analyzed from the Kounanis et al meta-analysis. The studies chosen for review from the meta-analysis were those that exhibited the greatest power, had the most strength as an 
observational study, and had the most precise method for validating PPD.

A subsequent meta-analysis published by Almeida et al in BMC Women's Health (2020) reviewed the association between labor epidural analgesia and postpartum depression. The primary outcome was a positive screen of PPD among women who received or did not receive labor epidural analgesia up to 3 months into the postpartum period. Nine studies of 4,442 women conducted between 2014 and 2019 were included in the analysis. Aggregated effect of the studies that investigated PPD among women who received epidural analgesia compared to controls found no significant differences (OR 1.02, 95\% CI, 0.62 1.66). ${ }^{19}$ Overall, this meta-analysis showed a lack of association between the use of epidural analgesia and postpartum depression. These observational studies cannot account for unknown confounders, which can only be adequately managed by randomized clinical trials.

Although not included in the meta-analysis, a 2004 prospective follow-up study by Hiltunen et al assessed the incidence and risk of high EPDS scores according to mode of delivery and mode of pain relief during vaginal delivery. ${ }^{14}$ This group evaluated EPDS during the 1st week and again 4 months postpartum in 185 mothers. The adjusted risk of depressive scores during the 1st postnatal week was decreased in the epidural/paracervical group compared to deliveries without analgesia (OR 0.25, 95\% CI, 0.09-0.72), although there was no difference at 4 months postpartum. ${ }^{14}$ The sample size in this study was low. With a larger sample size, the researchers may have been able to see a significant difference in depressive scores between the two groups at 4 months postpartum as well.

Similarly, Ding et al performed a prospective cohort study using 214 parturients preparing for vaginal delivery, 107 of whom received labor epidurals. PPD was demonstrated in $14 \%$ (15 of 107) of those who received epidural labor analgesia and $34.6 \%$ (37 of 107) of those without epidural $(\mathrm{p}<0.0001)$, showing a statistically significant difference and thus suggestive that epidural was associated with a decreased risk of postpartum depression. $^{20}$ This difference in PPD incidence between both groups is quite high. This may be due to the fact that in these patients, the presence of depression was not assessed before childbirth. It is possible that women with high EPDS scores were less likely to receive labor epidural analgesia and were more prone to develop postpartum depression. ${ }^{20}$ One limitation to this study was that obese women $(>100 \mathrm{~kg})$ were excluded, which may have increased the risk for a selection bias and decreased the generalizability of the finding. Another limitation was that the women lost to follow up might have been depressed with the study favoring retention of non-depressed women. We surmise, however, that this was similar in both the epidural and non-epidural groups. It may affect the overall number of women that are diagnosed as clinically depressed by EPDS, but it should not affect the difference between the two groups.

Moreover, subsequent studies also confirm an association between labor analgesia and PPD. Suhutharan et al demonstrated a lower incidence of PPD with epidural analgesia in a case-control study from Singapore that assessed postpartum females from Nov 2010 to Oct $2013 .{ }^{10}$ Controls were the patients who scored less than 7 on EPDS and positive cases had confirmed PPD based on clinical assessments by psychiatrists using DSM-5 criteria. Of the 479 subjects in the study, 62 (12.9\%) exhibited PPD while 417 controls did not at 4-8 weeks post-delivery. Women with previous PPD or a family history of PPD were more likely to develop PPD $(61.5 \%)$ than women without a personal or family history of PPD (10.2\%), whereas mode of delivery was not associated with PPD. For the $68.7 \%$ of women who received epidural analgesia, the risk for PPD was significantly lower than those without an epidural: $10.0 \%$ vs $19.3 \%$ (OR 0.47, CI 0.27-0.8, $\mathrm{P}=0.0078$ ). Absence of epidural analgesia was associated with almost double the risk of PPD (adjusted OR 1.95, CI 1.04-3.66, $\mathrm{P}=0.0367$ ). Interestingly, nitrous oxide was not associated with a decreased risk of PPD; however, IM pethidine was associated with an increased risk of PPD. These findings are likely due to the inadequate analgesia during labor that nitrous oxide provides. One review examining its efficacy as a labor analgesic reported little change in maternal verbal and visual analog scale scores of pain during use in labor. ${ }^{21}$ Presumably, IM pethidine also did not provide adequate labor analgesia and also caused a sedative effect which was unsatisfactory in these women.

Likewise, a 2018 study evaluated labor pain and epidural analgesia effectiveness as a predictor of PPD. ${ }^{15}$ The investigation included 201 parturients who were mostly primiparous and delivering at term (mean 39 weeks) by spontaneous vaginal delivery. Pain was assessed before and during implementation of epidural by numeric pain scale and EPDS assessment at 6 weeks postpartum. The Improvement in pain (PIP) scale was used as a primary predictor. Using linear regression, the results demonstrated an association between higher improvements in pain and lower EPDS score $(\mathrm{r}=0.025 ; \mathrm{P}=0.002)$.

These findings suggest that labor analgesia may be associated with depression defined as scores higher than 10 on the EDPS. This relationship persisted after including known and 
possible predictors of EPDS scores in the model. Sensitivity analysis showed the relationship between analgesia and postpartum depression risk was mediated by the degree of pain improvement experienced under epidural analgesia. Authors of the study calculated a $45 \%$ improvement in pain with epidural analgesia is required to see a one-point reduction in EPDS score. Although the impact of a one-point reduction on the EPDS is up for discussion, it still demonstrates a statistically significant impact on PPD. One can suggest many women may be able to achieve greater than $45 \%$ pain improvement through usage of epidural which may lower EDPS scores further. An issue with the study is that there was no comparison to women who did not receive epidural analgesia and so it is difficult to know if the effect on PPD is related to the women's expectations with pain relief by the epidural or to the actual pain relief itself.

While the evidence towards the associated decreased incidence of PPD with labor epidural analgesia is compelling, other studies do not show PPD and labor epidural analgesia to be associated. Nahirney et al aimed to assess whether epidural analgesia is associated with a lower risk of PPD at 6 months postpartum, among a group of mothers with no depression at delivery, after controlling for selection bias and appropriate adjustment for confounding. ${ }^{22}$ The incidence of EPDS score of 10 or greater was $12.9 \%$ at 6 weeks and $13.3 \%$ of women screened positive for PPD at either 6 weeks or 6 months postpartum, with slightly higher proportions of PPD among older mothers and those with higher BMI. Controlling for BMI, epidural use was not significantly associated with PPD. This study, however, had a wide confidence interval (0.39-2.77) and may be masking a statistically relevant association. In addition, it was not randomized or controlled so there was still potential for many unmissed confounders. The sample size was small, and there were a large number of patients who withdrew from the study which could have led to biases. One other limitation was that it lacked a formal diagnosis of postpartum depression which is a critique for most of the studies that showed a positive association between labor epidural analgesia and PPD.

$\mathrm{Wu}$ et al performed a population-based, matched cohort study to evaluate for an association between intrapartum epidural use and maternal postpartum depression presenting for medical care. ${ }^{8}$ This study included all nulliparous women in Ontario, Canada from 2006 to 2012 without a history of depression, who had a term vaginal delivery. Primary exposure was intrapartum epidural use with the primary outcome being the onset of depression requiring medical care within 12 months postpartum. Secondary outcome was self-harm.
A total of 40,303 women receiving intrapartum epidural were matched 1:1 on age, year of cohort entry, and propensity score to an equal number of women who did not receive an epidural. Overall, the rate of new onset depression presenting to the healthcare system was $0.88 \%$ within 12 months postpartum. Intrapartum epidural use was not associated with maternal postpartum physician or hospital visits or selfharm. Limitation of the study is that they measured women seeking medical treatment and did not examine women seeking non-medical professionals such as therapists or psychologists. In addition, many women suffering from PPD may not have sought out any help, and thus, it is difficult to measure any association based off of medical visits alone.

Most recently, Sun et al hypothesized whether epidural labor analgesia could decrease the incidence of PPD in trial of labor after a previous cesarean (TOLAC) ${ }^{23}$ Using a multicenter, prospective, cohort study design in Shenzhen, China, patients were divided into an epidural analgesia group (n-263) and a no epidural analgesia group, $(n-160)$. Post-partum depression was assessed at 48 hours and 42 days after delivery using the EPDS with a positive EPDS score of 10 or higher at 42 days after delivery. Epidural analgesia during labor was significantly associated with a decreased risk of depression at both 48 hours and 42 days after delivery for TOLAC (OR, 0.209; 95\% CI, 0.096-0.429; $P<0.001)$ and (OR, 0.235; 95\% CI, $0.113-0.469 ; P<0.001)$, respectively. Although well powered, the study had some significant limitations including homogeneous Han Chinese population, PPD not being formally diagnosed by a psychiatrist, and EPDS not proven well validated on Chinese populations. Furthermore, this observational study could not determine whether there was a causal relationship between epidural labor analgesia and the decreased risk of PPD, showing correlation only.

Lastly, Orbach-Zinger et al conducted an observational study examining the relationship between birth plan, satisfaction with epidural, and postpartum depression. ${ }^{24}$ She hypothesized that the PPD rate at 6 weeks postpartum would be highest among women who intended to deliver with epidural anesthesia but did not have it, explained by both untreated labor pain and their unmatched expectations during labor. Women $>37$ weeks gestation who delivered vaginally were eligible $(\mathrm{N}=1326)$ were divided into 4 groups by those who wanted an epidural but did not receive one; those who did not want one but received one; those that wanted an epidural and received one; and those who did not want one and did not receive one. At postpartum day 1, these women filled out satisfaction questionnaires and followed up at 6 weeks with administration of 
EPDS. The primary outcome was diagnosis of PPD defined as EPDS $>10$. The overall incidence of PPD was $6.6 \%$ with the PPD rate at 6 weeks in the group that wanted an epidural but did not receive one showing no statistical difference from the rest of the cohort $(\mathrm{RD}=1.8 \%, 95 \% \mathrm{CI},-0.03-0.07, \mathrm{P}=0.371)$. Comparing the relative risk for PPD in women who did not deliver with an epidural, PPD was higher in women who wanted an epidural but did not receive one versus those who did not want one and did not receive one. Although it did measure a direct relationship between PPD and epidural use, this study found that delivering with unmatched expectations was another risk factor for PPD at 6 weeks. Limitations of this study were that important variables were not included that could affect the depression outcome such as patient level of education, family history of depression, or depressive symptoms prior to epidural placement. Also, pain at 6 weeks postpartum was not assessed in this study which could negatively impact these women's quality of life.

\section{Discussion}

Post-partum depression is a debilitating disease which poses significant burdens on both the mother and the family. Identifying risk factors in an attempt to mitigate PPD could decrease the risk and severity of the disease. The most well-established risk factor for PPD is a history of mood disorders. However, with lack of concise data, the relationship between PPD and epidural analgesia is less clear. As shown through the above discussion, there is substantial heterogeneity in the methods, covariates and outcomes of different studies. Even with the Kountanis et al and Almeida et al meta-analyses, both well-powered studies, it is quite difficult to standardize and control for confounding factors and differential inclusion of the available literature. The results of these meta-analyses could be significantly altered if standardized diagnosis criteria had been employed. As per DSM-5, PPD diagnosis can be made if depression occurs within one year following birth. Most studies had diagnosed PPD much earlier with a lack of long-term follow-up.

Furthermore, many of these studies did not account for certain subgroups (ie, previous history of PPD, family history of PPD, co-morbid psychiatric disorders, breastfeeding) that may have had a greater benefit from epidural analgesia. For example, Nahirney et al excluded women which had suspected depression at delivery (EPDS >13) and Orbach-Zinger et al completely excluded all women on antidepressant therapy. Many other confounding risk factors such as poor social supports, abuse history, expectations and views on pregnancy and infant outcomes were not taken into consideration with the majority of studies. As such, these factors and limitations may be greatly skewing this data set, missing certain subgroups, and it is difficult to extrapolate any meaningful association regarding PPD and epidural use.

Further critiques of the manuscripts presented and analyzed in the Kountanis et al study is that over half of the studies included were deemed to be of "poor" quality based upon criteria from the Agency for Healthcare Research and Quality (AHRQ). This was mostly due to the lack of comparability between cohort groups and the inability to account for and explain the individuals who were lost to follow-up. To date, some of the literature available on this topic suggests that labor epidural analgesia is associated with a decrease in incidence of postpartum depression. There are, however, other articles that fail to demonstrate this association.

Overall, it has been established that epidural analgesia significantly reduces pain associated with labor. Although both meta-analyses failed to find an association between epidural use and reduction in PPD, further well-designed studies on this topic need to be investigated in order to substantiate the current evidence in the literature. As the various study designs and data are so heterogeneous in nature, it is difficult to make any conclusion from these well-powered meta-analyses. In addition, investigation as to specific patient demographics who may benefit the most, the degree to which pain reduction results in decreased severity of PPD, along with its relationship on the long-term scale still must be elucidated.

None of the studies discussed were randomized controlled trials which could control for confounding factors. Women who refuse epidural analgesia may even have the highest risk for PPD. It is difficult to externally validate these cohort studies as women of varying populations and ethnicities emotionally deal with pain and labor differently, and some cultures may be more prone to PPD than others. As mentioned, an ideal study design would be a randomized, controlled trial with clinical diagnosis of postpartum depression; however, it would be difficult to perform this type of study. The diagnosis of PPD differs in many of the studies which affects the outcomes acquired by the researchers. This needs to be standardized in all studies in order to be able to accurately compare their results. One good study would be to randomize parturients in labor into different pain-relieving method groups (IV 
remifentanil, nitrous oxide) against epidural analgesia with using PPD as the primary endpoint.

\section{Conclusion}

This literature review provides equitable evidence for both the value of epidural analgesia on PPD, as well as examination of the lack thereof. It is the hope that bringing attention to this cross-specialty topic can aid obstetricians, psychiatrists and anesthesiologists in providing better patient outcomes for this population. It is clear epidural analgesia is a technique that provides many positive outcomes during labor. Based on the current literature reviewed, its ability to potentially decrease the incidence of PPD may serve another acceptable reason why its use should be encouraged during labor but more data is needed presently.

\section{Disclosure}

The authors reported no conflicts of interest for this work.

\section{References}

1. Stewart DM, Vigod S. Postpartum depression. $N$ Engl J Med. 2017;376(9):895.

2. American Psychiatric Association. Diagnostic and Statistical Manual of Mental Disorder. 5th ed. Arlington, VA: American Psychiatric Publishing; 2013.

3. Goodman JH. Postpartum depression beyond the early postpartum period. J Obstet Gynecol Neonatal Nurs. 2004;33:410-420. doi:10.1177/0884217504266915

4. Wisner KL, Sit DKY, McShea MC, et al. Onset timing, thoughts of self-harm, and diagnoses in postpartum women with screen-positive depression findings. JAMA Psychiatry. 2013;70:490-498. doi:10.1001/ jamapsychiatry.2013.87

5. Eisenach JC, Pan PH, Smiley R, Lavand'homme P, Landau R, Houle TT. Severity of acute pain after childbirth, but not type of delivery, predicts persistent pain and postpartum depression. Pain. 2008;140(1):87-94. doi:10.1016/j.pain.2008.07.011

6. Adouard F, Glangeaud-Freudenthal NM, Golse B. Validation of the Edinburgh postnatal depression scale (EPDS) in a sample of women with high-risk pregnancies in France. Arch Womens Ment Health. 2005;8(2):89-95. doi:10.1007/s00737-005-0077-9

7. Bloch M, Schmidt PJ, Danaceau M, Murphy J, Nieman L, Rubinow DR. Effects of gonadal steroids in women with a history of postpartum depression. Am $J$ Psychiatry. 2000;157:924-930. doi:10.1176/appi.ajp.157.6.924

8. Wu YM, McArthur E, Dixon S, Dirk JS, Welk BK. Association between intrapartum epidural use and maternal postpartum depression presenting for medical care: a population-based, matched cohort study. Int J Obstet Anesth. 2018;35:10. doi:10.1016/j.ijoa.2018.04.005
9. Jonas W, Nissen E, Ransjö-Arvidson AB, Matthiesen AS, Uvnäs-Moberg K. Influence of oxytocin or epidural analgesia on personality profile in breastfeeding women: a comparative study. Arch Womens Ment Health. 2008;11(5-6):335-345. doi:10.1007/s00737-008-0027-4

10. Suhitharan T, Pham TP, Chen $\mathrm{H}$, et al. Investigating analgesic and psychological factors associated with risk of postpartum depression development: a case-control study. Neuropsychiatr Dis Treat. 2016;12:1333-1339. doi:10.2147/NDT.S105918

11. Silva M, Halpern SH. Epidural analgesia for labor: current techniques. Local Reg Anesth. 2010;3(3):143. doi:10.2147/lra.s10237

12. Hawkins JL. Epidural analgesia for labour and delivery. $N$ Engl J Med. 2010;362:150310. doi:10.1056/NEJMct0909254

13. Shen X, Li Y, Xu S, et al. Epidural Analgesia During the Second Stage of Labor: A Randomized Controlled Trial. Obstet Gynecol. 2017;130(5):1097-1103. doi:10.1097/AOG.00000000000002306

14. Hiltunen P, Raudaskoski T, Ebeling H, Moilanen I. Does pain relief during delivery decrease the risk of postnatal depression? Acta Obstet Gynecol Scand. 2004;83(3):257-261. doi:10.1111/j.0001-6349.2004.0302.x

15. Lim G, Farrell LM, Facco FL, Gold MS, Wasan AD. Labor analgesia as a predictor for reduced postpartum depression scores: a retrospective observational study. Anesth Analg. 2018;126 (5):1598-1605. doi:10.1213/ANE.0000000000002720

16. Lim G, LaSorda KR, Farrell LM, et al. Obstetric pain correlates with postpartum depression symptoms: a pilot prospective observational study. BMC Pregnancy Childbirth. 2020;20(1). doi:10.1186/s12884020-02943-7

17. Gaudet C, Wen SW, Walker MC. Chronic perinatal pain as a risk factor for postpartum depression symptoms in Canadian women. Can J Public Health. 2013;104(5):e375-87. doi:10.17269/cjph.104.4029

18. Kountanis J, Vahabzadeh C, Bauer S, et al. Labor epidural analgesia and the risk of postpartum depression: a meta-analysis of observational studies. J Clin Anesth. 2020;61:109658. doi:10.1016/j.jclinane.2019.109658

19. Almeida M, Kosman KA, Kendall MC, et al. The association between labor epidural analgesia and depression: a systematic review and meta-analysis. BMC Women's Health. 2020;20(1). doi:10.1186/ s12905-020-00948-0

20. Ding T, Wang DX, Qu Y, Chen Q, Zhu SN. Epidural labor anesthesia is associated with decreased risk of postpartum depression: a prospective cohort study. Anesth Analg. 2014;119(2):383-392. doi:10.1213/ANE.0000000000000107

21. Rosen MA. Nitrous oxide for relief of labor pain: a systematic review. Am J Obstet Gynecol. 2002;186:S110-S126. doi:10.1016/ S0002-9378(02)70186-5

22. Nahirney M, Metcalfe A, Chaput KH. Administration of epidural labor analgesia is not associated with a decreased risk of postpartum depression in an urban Canadian population of mothers: a secondary analysis of prospective cohort data. Local Reg Anesth. 2017;10:99-104. doi:10.2147/LRA.S141569

23. Sun J, Xiao Y, Zou L, et al. Epidural labor analgesia is associated with a decreased risk of the edinburgh postnatal depression scale in trial of labor after cesarean: a multicenter, prospective cohort study. Biomed Res Int. 2020;2020. doi:10.1155/2020/2408063

24. Orbach-Zinger S, Landau R, Harousch AB, et al. The relationship between women's intention to request a labor epidural analgesia, actually delivering with labor epidural analgesia, and postpartum depression at 6 weeks: a prospective observational study. Anesth Analg. 2018;126 (5):1590-1597. doi:10.1213/ANE.0000000000002501 


\section{Publish your work in this journal}

The Journal of Pain Research is an international, peer reviewed, open access, online journal that welcomes laboratory and clinical findings in the fields of pain research and the prevention and management of pain. Original research, reviews, symposium reports, hypothesis formation and commentaries are all considered for publication. The manuscrip

management system is completely online and includes a very quick and fair peer-review system, which is all easy to use. Visit http:// www.dovepress.com/testimonials.php to read real quotes from published authors. 